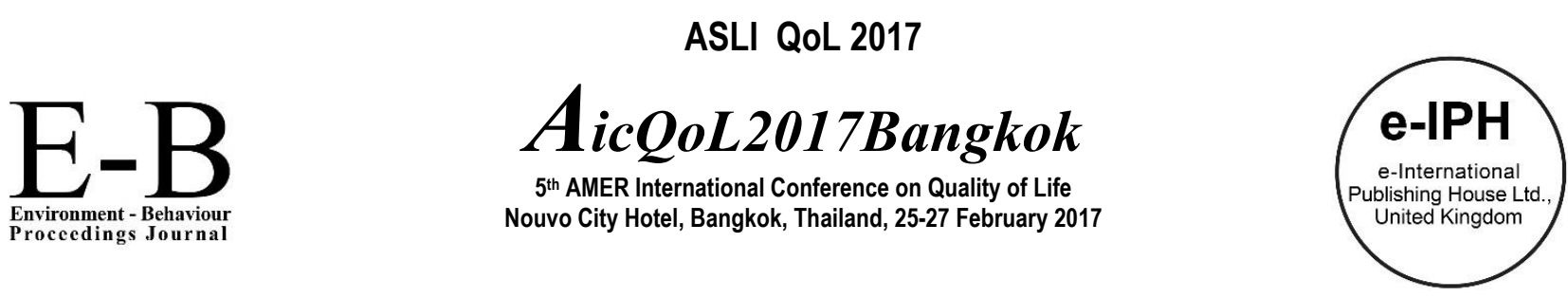

\title{
Comparison of Concept Transferring Procedures of Basic Idea between Handmade Design and Computer Modeling
}

\author{
Pracha Pijukkana ${ }^{1 *}$, Yanin Rugwongwan ${ }^{1}$ \\ ${ }_{1}^{1}$ Faculty of Architecture, King Mongkut's Institute of Technology Ladkrabang (KMITL), Bangkok, 10520, Thailand.
}

\begin{abstract}
This research aims to make a comparative study of the performance results between creating the basic idea designs by handmade design process and by computer modeling process. The study of product design by using handmade process and computer modeling process has the same objectives which are to generate ideas and encourage creativity in product design. Though these two processes are done by using different tools, they have the same idea of using the interactive between brain, hand, and forms that appear on the paper or on the computer to improve and Idea Development, Sketch Design. Also, these two processes are used as an approach to teach and learn industrial product design, they can be chosen to suit students with different features and can be used to increase academic achievement performance.
\end{abstract}

Keywords: Basic Idea, Handmade Design, Computer Modeling, Industrial Product Design.

ISSN: 2398-42870 2017. The Authors. Published for AMER ABRA by e-International Publishing House, Ltd., UK. This is an open access article under the CC BYNC-ND license (http://creativecommons.org/licenses/by-nc-nd/4.0/). Peer-review under responsibility of AMER (Association of Malaysian Environment-Behaviour Researchers), ABRA (Association of Behavioural Researchers on Asians) and cE-Bs (Centre for Environment-Behaviour Studies), Faculty of Architecture, Planning \& Surveying, UniversitiTeknologi MARA, Malaysia.

\section{Introduction}

Industrial design is another faculty that has an increasing role in today's society. These increasing roles can be seen through the design of the products which are more emphasized on the beauty, interesting and usefulness of the products. The product design that applied the mentioned design principles can create mental values to the human being. The design creativity must be based on attractiveness and can create the imagination to those who see the products to understand the design concepts. The product designers have important roles in the everyday life of human being, and they also control the formats and the functionalities of the products. Product designers transfer their ideas through drawing and detailing. In order to create and produce products that are useful and meet the human need, the product design students develop their understanding of a result of choosing the designing method. Thus, the developing of the design skills is very important for the designers to analyze the products and to develop creative solutions (Authority,2013).The process of transferring ideas is a very important principle and an important guideline for designing products that would lead to the target design systematically, or it can be used as a framework in the designing process by using the data based on the design ideas to help the designers to achieve the desirable target. Since each designer has different degree of conceptual ideas and different designing methods, thus the purpose of this research is to do a comparative study of the performance results between creating the basic conceptual design ideas by handmade process and by computer modeling process. The learning and teaching of these two designing process have the same goal which is to create the ideas and supporting the creativity in product design. However, these two designing methods have different steps and different tools to make the interaction between the brain, hand, and sketches that appear on the paper or on the computer.

\footnotetext{
${ }^{*}$ Corresponding author. Tel.: +66 814037546

E-mail address.ton_pracha@hotmail.co.th
}

ISSN: 2398-4287@ 2017. The Authors. Published for AMER ABRA by e-International Publishing House, Ltd., UK. This is an open access article under the CC BYNC-ND license (http://creativecommons.org/licenses/by-nc-nd/4.0/). Peer-review under responsibility of AMER (Association of Malaysian Environment-Behaviour Researchers), ABRA (Association of Behavioural Researchers on Asians) and cE-Bs (Centre for Environment-Behaviour Studies), Faculty of Architecture, Planning \& Surveying, UniversitiTeknologi MARA, Malaysia. 


\section{Literature Review}

Sahachaisaeree mentions that "Designers usually involve in designing different forms". Though, designers use the element of design and principle of design, which are the important designing factors similar to materials and designing processes, professional designers also use strategies and skills which derived from practicing the interaction between brain, hand and sketches which appears on papers (Laseau, 2001). This process is called Graphic thinking which is consistent with Design development spiral of Zeisel.The process of Graphic thinking begins with transferring the images from the brain through hand onto the papers; the brain will respond to the basic ideas that appear on the papers through the eyes to analyze and adjust. This graphic thinking process begins from brain through hand and onto the papers and it will happened again and again until the design is satisfied. The design development spiral happens after the designers get the basic design, they usually make changes to the original design and develop it until they find the most appropriate one (Sahachaisaeree, 2004; Zeisel, 1981). Currently, there are two popular design idea transferring processes that often use to present the sketch of the products in product design program which are handmade design and computer modeling process.

Handmade design is a product design process that applied 3D design onto 2D paper. Handmade design is one of design methods that are used to pass on the imagination of the designers onto the papers by using pencils or other tools depend on the designers' attitude. The handmade design has flexibility in designing, and can create good imagination. Handmade design often uses to record spontaneous ideas and use to survey the optional designs. The key benefit of sketching in other areas such as product design and architectural design are to help designers to develop the ideas in creating different styles; such as new forms and shapes, more quickly and with more flexibility (Scho"n, 1992).Drawing technique is an important skill for design, sometimes sketch drawing is an important element that will be used to determine the direction of the design process and to lay the fundamental to see the beauty details or the ideas during the beginning of design process. Nowadays, the words sketching and drawing are wildly used to explain the activities of the designers and artists (Yusoff, 2007). The sketching technique beside using pencil or pen to draw on the papers is to use other tools in order to make the sketches look more real or to increase the understanding of product communications, these tools are such as markers, watercolor, colored pencils, color posters or other tools depending on the aptitude of the designers; however, the sketch elements still remain the same.

Sketch design by computer modeling is the process that uses Computer Aided Design (CAD) to help creating the designs. CAD is a 3D modeling, and the development of 3D modeling computer will help creating the designs that have forms and dimension that are more realistic because CAD is the art-based software. Computer Aided Design can create high-quality and realistic 3D designs, and it can stimulate accurate dimension. Therefore, using computer modeling is very helpful to create the designs because it can stimulate accurate angles. Especially in the final production process, in this process, every aspect of the design will be refined, all parts of the design will be developed, and the possibility to produce the product will be investigated. Thus, Computer-Aided Design can help create all designs, it can help complete all the works, and make it possible to produce the initial ideas (Duku, 2014). Computer-Aided Design is a tool that has been proven to have high-performance for designing support such as analysis or production. Also, it can be useful for designing choice or it can be used as the design guidelines for the new design (Woodbury, 2006).

Table1: Comparing between handmade design process and computer modeling process

\begin{tabular}{lll}
\hline Details & Handmade Design & Computer Modeling \\
\hline Type of design & $2 \mathrm{D}$ & 3D \\
\hline Drawing method & $\begin{array}{l}\text { Use hand drawing to draw lines such as straight line, horizontal line, } \\
\text { vertical line, diagonal line, and arch, etc., to create the products. }\end{array}$ & $\begin{array}{l}\text { Use CAD to draw geometry shapes such as rectangular } \\
\text { shape, cylinder shape, cone shape and sphere shape, etc. } \\
\text { and use the cutting design to create the products }\end{array}$ \\
\hline Viewing angle & One viewing angle & 360degree viewing angle \\
\hline
\end{tabular}

\section{Methodology}

This research selects the sample groups from random samples, which are the non-probability sampling, who are the undergraduate students from the 4th year's industrial product design program from Rajamangala University of Technology Phra Nakhon. The sample group of 56 students will be divided base on their academic standing and their aptitude in sketch design process. One of the students will be chosen to make the sketch design using both handmade design and computer modeling process within the same time frame. The number of sketches/ time will be recorded, in each experiment, the time will be increased by 30 minutes, the experiment will be repeated until the time reach 120 minutes. After that, the professor will evaluate the quality of the designs that can be used in the development of the industrial products.

\section{Data Collection}

The researchers will synthesise the process of transferring the basic ideas in order to present the sketches of the undergraduate design students, to find the point that will be used as the indicator for the assessment, and to create tools that will be used to evaluate the learning and teaching industrial design. The data collecting methods will be divided into three steps as follows.

- Collecting the academic performance data (Transcript) of the 4th year undergraduate industrial design students and divided the students into groups by using Cluster Analysis to find the attitudes indication factors. Dividing the academic performance into two parts, the first part is the Grade Point Average (GPA) which can be divided the student according to their GPA into three groups; the group of students that have high GPA in industrial product design 1-3 class, sketching class, and painting techniques class and other classes that involve hand sketching will be classified as the classes that have an aptitude in handmade drafting. However, if the 
students have high GPA in industrial product design 4-5 classes, computer for design and production classes and other classes that involve using computers to create the designs will be classified into the group that has an aptitude in using computer for design process

- Survey the programs computer that is used for making the product designs by the 4th year students in order to explore the usage level of the 3D design programs

- Testing the concept of the idea sketching by choosing the required group from the Non-probability Sampling. The students from the selected groups will be asked to create the designs by using both the handmade design process and computer modelling process. The given designs for handmade process and computer modelling process will be different: however, it will have similar degree of difficulty. This is because if the students have the experience of making the same design over and over again, they will tend to develop the Idea Development instead of creating idea sketch. The winning design will be chosen from the products that can transfer the idea sketch which can also create many imaginations. In this research, the researchers ask the group that use handmade design process to make a design for toaster and ask the computer modelling process group to create a design for rice cooker. These two products design has the similar level of difficulty and complexity. The designs will be sketched by hand on 100 pounds papers or by computer using the A2 $(420 \times 594 \mathrm{~mm})$ size paper. These designs challenge will lead to the idea development in the next design steps.
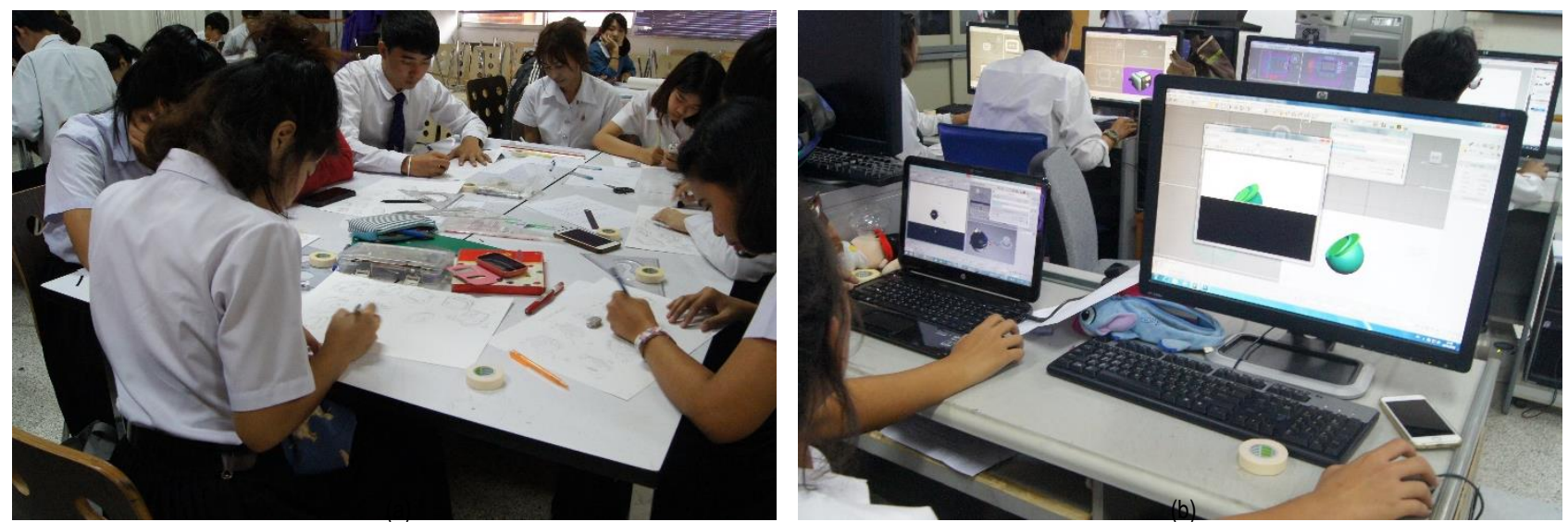

Fig. 1. (a) Handmade design process; (b) Computer modelling process.
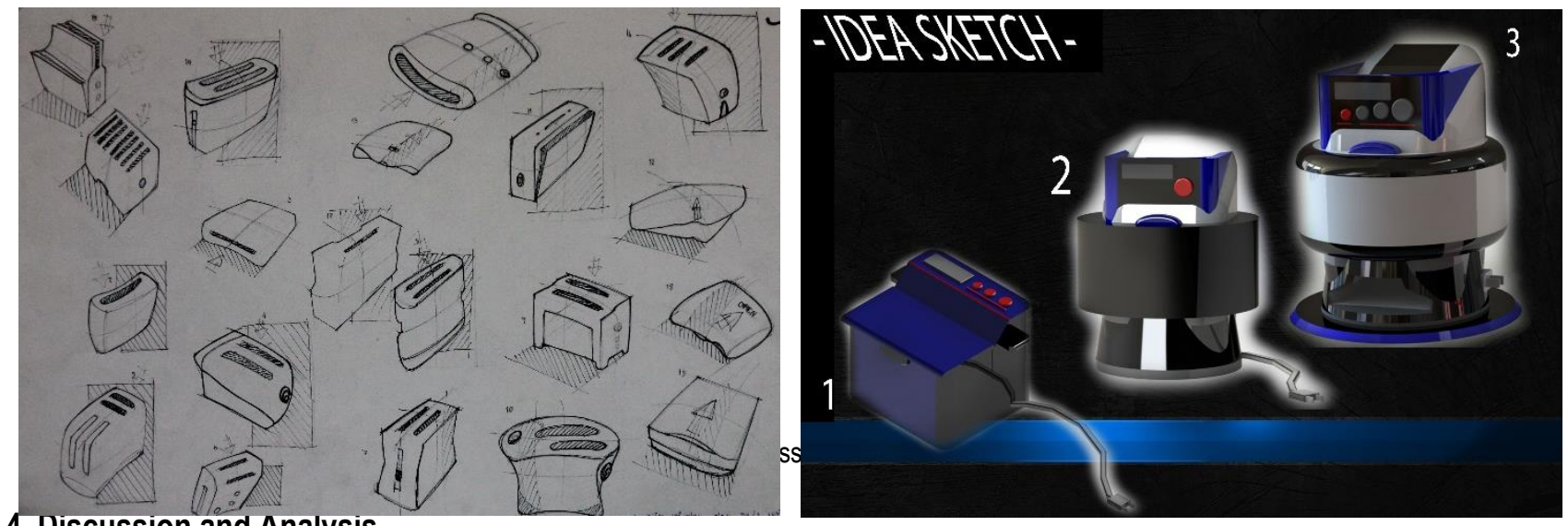

\section{Discussion and Analysis}

From testing idea sketches, 56 students of the 4th-year undergraduate industrial design are asked to create idea sketches by handmade process and computer modeling process. Each round, the students had 15 minutes to create the designs, and the designing process will continue until the time reach 120 minutes. The analysis results found that handmade design process can create the average of 16.43 sketches per 15 minutes which is more than the computer modeling process which can only create the average of 6.93 sketches per each 15 minutes.

From examining the difference between the average number of sketches between handmade design process and computer modelling process which each process is not independent to each other, the analysis result yielded that each test period and the total period (120 minutes), the handmade process and the computer modelling process have the statistically significant difference at the 0.05 (see Table.2) 
Table2: Comparing the basic idea sketch transferring process between handmade design and computer modeling.

\begin{tabular}{lllllll}
\hline \multirow{2}{*}{ times/number of sketches (minute) } & \multicolumn{2}{c}{ Handmade Design } & \multicolumn{2}{c}{ Computer Modeling } & \multicolumn{3}{l}{ Paired Samples Test } \\
\cline { 2 - 7 } & $\bar{X}$ & S.D. & $\bar{X}$ & S.D. & t & P \\
\hline $0-15$ & 2.36 & 1.66 & 0.82 & 0.77 & 6.62 & 0.00 \\
$16-30$ & 2.54 & 1.39 & 1.02 & 0.77 & 6.83 & 0.00 \\
$31-45$ & 2.09 & 0.82 & 0.96 & 0.79 & 8.49 & 0.00 \\
$46-60$ & 2.48 & 0.93 & 0.89 & 0.76 & 11.06 & 0.00 \\
$61-75$ & 2.02 & 0.86 & 0.84 & 0.76 & 8.88 & 0.00 \\
$76-90$ & 1.79 & 0.93 & 0.84 & 0.78 & 6.52 & 0.00 \\
$91-105$ & 1.79 & 1.64 & 0.86 & 0.75 & 4.00 & 0.00 \\
$106-120$ & 1.37 & 1.32 & 0.70 & 0.74 & 4.15 & 0.00 \\
Total time & 16.43 & 6.07 & 6.93 & 4.60 & 11.51 & 0.00 \\
(120minutes) & & & & & &
\end{tabular}

Statistic displays of the analysis of variance tests indicate the differentiating factors between each testing periods that have the effect on the number of sketches during the idea sketch transferring process. By using students' GPA data, it can separate students into three groups. First is a group of students who have low GPA and have the lowest average number of sketches, which are 3.14 sketches. Next is a group of students who have the average GPA and have the average number of sketches which is 4.38 sketches. Last is a group of students who have high GPA and also have the highest average number of sketches, which are 4.92 sketches. However, the total testing time has no interaction with each group of students. This means different GPA does not have an effect on the idea sketch transferring process. However, during the test period, $0-15$ mins $F(2,109)=15.40, p=.00$ during the test period1630 mins $F(2,109)=3.38, p=.04$ during the test period106-120 mins $F(2,109)=-3.87, p=.02$ has statistical significant different at 0.05 (see Table.3)

Table3: Comparing the idea sketch transferring process from students' GPA

\begin{tabular}{|c|c|c|c|c|c|c|c|c|}
\hline \multirow{2}{*}{$\begin{array}{l}\text { Period/number of } \\
\text { sketches(minute) }\end{array}$} & \multicolumn{2}{|c|}{ Low level } & \multicolumn{2}{|c|}{ Medium level } & \multicolumn{2}{|c|}{ High level } & \multicolumn{2}{|c|}{ ANOVA } \\
\hline & $\bar{X}$ & S.D. & $\bar{X}$ & S.D. & $\bar{X}$ & S.D. & $\mathrm{F}$ & $P$ \\
\hline $0-15$ & 0.81 & 0.53 & 1.48 & 0.72 & 1.94 & 1.24 & 15.40 & 0.00 \\
\hline $16-30$ & 1.47 & 1.00 & 1.43 & 0.99 & 2.19 & 2.05 & 3.38 & 0.04 \\
\hline $31-45$ & 1.72 & 1.45 & 1.55 & 0.90 & 2.00 & 1.69 & 1.03 & 0.36 \\
\hline $46-60$ & 1.31 & 0.95 & 1.45 & 1.01 & 1.72 & 0.97 & 1.68 & 0.19 \\
\hline $61-75$ & 1.67 & 1.37 & 1.63 & 1.01 & 1.69 & 1.19 & 0.03 & 0.97 \\
\hline $76-90$ & 1.28 & 1.11 & 1.55 & 0.99 & 1.44 & 0.94 & 0.69 & 0.50 \\
\hline $91-105$ & 1.19 & 1.04 & 1.33 & 0.80 & 1.44 & 1.05 & 0.61 & 0.55 \\
\hline $106-120$ & 0.94 & 0.86 & 1.05 & 0.99 & 1.75 & 1.95 & 3.87 & 0.02 \\
\hline Total time & 3.14 & 2.79 & 4.38 & 4.76 & 4.92 & 5.08 & 1.59 & 0.21 \\
\hline
\end{tabular}

\section{Conclusion and Recommendations}

From the experiment result, it shows that handmade design and Computer Modeling design have different beginning process and have different tools. However, these two designing methods support the creativity in product design, and they both require the thinking process from brain eyes hands. The differences between these two idea sketch processes have the effects on teaching and learning industrial design. The research found that handmade design is an idea transferring process that helps increasing the imagination in idea sketch. Also, handmade design can draw more sketches and more variety of product designs than sketching via the computer modeling. Since drawing the creative design by hand is often used to sketch the spontaneous ideas and it helps the designers to develop different design ideas such as shapes and forms faster and more flexible (Scho"n, 1992). On the other hand, the computer modeling process has the advantages in adjusting the images, colours and proportions. On the contrary, if the designers do not know how to use the computer modeling properly, using it might limit their imagination (Yusoff, 2007). Computer modeling process might be appropriate for developing the ideas (Idea Development) and design drafts (Sketch Design).

Using the GPA of the students to determine their efficiency in transferring the idea sketch, the professor should investigate students' background and their past GPA standings before mixing students with different academic performance together (Ruengtam, 2014). The experimental results show that the group of students who have low GPA also have a lower than an average number of sketches. The groups of students, who have medium GPA, also have an average number of sketches. While the group of students with high GPA, also have the highest number of sketches. The group of students with high GPA is projected be the students who have effective initiation and have freedom of learning and creative thinking (NorshidahNordin, 2016). Overall, the difference in academic achievement of the students does not affect the idea sketch transferring process. Nowadays, students have different thinking process, which might be due to their own background; they can access the knowledge in the form of critical knowledge synthesis and selfexploration. Moreover, they can recognize the difficulty and complexity of the designs and the individual differences in term of learning style, design ability and communication skills (Mohamad Adi, 2015).

The recommendations for this research will be used as the guidelines for teaching industrial design which is suitable for time management and the process of transferring the idea sketch. Also, it can be used as guidelines for students with different characteristics in order to increase their academic achievement performance since the basic idea sketch is an important foundation for improving or developing the ideas (Idea Development) and design drafts (Sketch Design). 


\section{Acknowledgements}

The author would like to thank Assoc. Prof. Dr.NopadonSahachaisaeree and Asst. Prof. Dr.YaninRugwongwan, Faculty of Architecture, King Mongkut's Institute of Technology Ladkrabang, Thailand, for their kind suggestions, guidance, and support to the researcher. I also would like to thank Faculty of Architecture and Design, Rajamangala University of Technology Phra Nakhon, Thailand, for a scholarship to pursue my PhD course work and dissertation.

\section{References}

Authority, V. C. (2013). Product Design and Technology. Victoria, Australian: Victorian Curriculum and Assessment Authority.

Duku. (2014, October 20). CAD (Computer Aided Design). Retrieved from http://www.duku-design.co.uk/cad.html

Laseau, P. (2001). Graphic thinking for architects and designers. London: Vanostand.

Mohamad Adi, F. e. (2015). Conceptualisation as Key Factor in Seizing. Journal of ASIAN Behavioral Studies, 5(20), 13-23.

Nordin, N. e. (2016). Assessing Readiness for Self-Directed Learning among College Students in the Provision of Higher Learning Institution. 7thAcE-Bs2016Taipei (pp. 91-101). Taiwan: AMER ABRA.

Ruengtam, P. (2014). Cooperative/Collaborative Learning in an Interior Architectural Program. Journal of ASIAN Behavioural Studies, 4(17), 31-40.

Sahachaisaeree, N. (2004). Sustainable paradigm in interior design. Bangkok: Kasembundit University.

Scho"n, D. A. (1992). Kinds of seeing and their functions in designing. Design Studies, 13(2), 135-156.

Woodbury, R. F. (2006). Whither design space" artificial intelligence. Analysis and Manufacture, 20(2), 63-82. doi:10.1017/S0890060406060057.

Yusoff, S. B. (2007). Automotive Sketching Techniques from Education and Professional Practice. Birmingham City: Birmingham City University.

Zeisel, J. (1981). Inquiry by design: tools for environment-behavior research. Cambridge: Cambridge University. 